\title{
Liposuction: A Surgical Tool to Improve the Quality of Life after Morbid Medical Conditions: Review of Literature
}

\section{Hamdy A Elkhatib*}

Senior Consultant and Head of Plastic and Hand Surgery, Alkhor Hospital, Hamad Medical Corporation, Doha, Qatar and Adjunct Assistant Professor of Plastic Surgery, Weill Cornell, School of Medicine, State of Qatar, Qatar

"Corresponding author: Hamdy A Elkhatib, MD, Senior Consultant and Head of Plastic and Hand Surgery,

Alkhor Hospital, Hamad Medical Corporation, Doha, Qatar and Adjunct Assistant Professor of Plastic Surgery, Weill Cornell, School of Medicine, State of Qatar, Qatar, Tel: 00974-77719988; E-mail: hamdya24@yahoo.com

Received date: May 17, 2014, Accepted date: July 29, 2014, published date: August 04, 2014

Copyright: @ 2014 Elkhatib HA. This is an open-access article distributed under the terms of the Creative Commons Attribution License, which permits unrestricted use, distribution, and reproduction in any medium, provided the original author and source are credited.

\begin{abstract}
Introduction: The purpose of this literature review is to conduct a systematic review of the clinical applicability and safety of the liposuction technique and to familiarize the reader with the scope of non-cosmetic indications.

The procedure of liposuction used not only as a tool of rejuvenation but also used to improve the quality of life after many disabling medical conditions such as:

Lipomatosis syndromes, Adipose tissue diseases, chronic lymphedema of the extremities, fasciocutaneous, and myocutaneous bulky Flaps, subcutaneous lipomas, axillary Hyperhydrosis, post ablative surgery and Radio dermatitis.

Methods: An online search of the Cochrane Library, MEDLINE, Embase and SciELO was conducted. Studies included in the review were 47 original articles reported from 1982 to February 2014. The articles included the use of liposuction for treatment of non-cosmetic and disabling medical conditions, with description of clinical applications and complications. The criteria used for papers selection were: papers with large size of samples, papers with significant statistics, and original papers. The case reports were excluded.

Results: There was a broad agreement in the reviewed literature about the applicability and the efficacy of the liposuction for treatment of these chronic medical conditions. Literatures review confirmed that this technique has provided significant and stable cure.

Conclusion: Liposuction is the most frequent aesthetic procedure world-wide for adipose tissue reduction and treatment of lipedema. Apart from aesthetic indications, liposuction also is suitable for treatment of chronic medical diseases and non-cosmetic conditions. It alternates some of surgical procedures like debulking of flaps, undermining the subcutaneous tissues. It is an adjuvant tool for breast reconstruction. Liposuction is not a simple procedure but requires extensive knowledge and experience to prevent irreversible medical or aesthetic complications.
\end{abstract}

Keywords: Liposuction; Rejuvenation; Aesthetic indications; Breast reconstruction; Lipomatosis syndromes

\section{Historical Review}

The ancient Egyptian mummification methods 5000 years ago were based on removal of the whole internal organs and subcutaneous fat except the heart [1].

The traditional dry Liposuction technique was introduced more than 50 years ago. The term liposculpture was introduced by Teimouria and Fischer [2] and Fournier [3] who advocated also the criss-crossing technique.

Illouz [4] developed the wet, tumescent liposuction technique that helped in standardization and refinement of this surgical tool.

Field [5] in 1977 was the first American dermatologist who introduced the procedure in USA using the Fischer's suction machine.
The first American liposuction course was taught 1982 by Dolsky and Newman [6].

In 1987, Klein [7] developed a formula of $0.05 \%$ lidocaine, 1:1,000,000 epinephrine, and $10 \mathrm{~mL}$ of bicarbonate and a litre of normal saline. The Klein formula allowed large liposuction to bed one under local anesthesia and provided patient a painless 24 hours postoperatively.

Zocchiin [8], presented a totally revolutionary way to interpretate the body contouring using a new technique based on the surgical use of ultra sound energy, allows the selective destruction of lipocytes by means of cavitation and elimination of the fluid fraction (fattyacids). The ultra sound wave stimulates the collagen in the deep dermis and initiates lifting of the skin.

Apfelberg [9] described the use of laser assisted lipolysis. There is no scientific evidence demonstrates the advantage this technique over the ultra sound assisted liposuction or the traditional liposuction. 
Blugeman et al. [10] described a novel technique, the radio frequency assisted liposuction, the procedure was tolerated nicely, safe and efficient in removal of a moderate volume of fat. Paul [11] reported on the three dimension skin tightening after the radio frequency assisted liposuction and proposed a mechanism of tissue tightening

The Water-Jet assisted liposuction $\mathrm{s}$ a new technique for body contouring that relies on a fan-shaped jet of tumescent solution to anaesthetize the area for liposuction. Sasaki [12] used his technique in 2011 on forty one patients and have emphasized on its efficacy and its safety.

\section{The role of Liposuction for treatment of different medical conditions}

\section{Adipose tissue diseases}

The author [13] has used the wet technique to treat the unusual fat distribution of the lower part of the body which is clinically characterized by massive symmetric and diffuse fat deposition in the trochanters, groins, buttocks, hips, and lower extremities; it contrasts sharply with the normal upper part of the body. The massive lipomatoses of the lower part of the body can be classified into 3 types: type 1 , the familial symmetrical lipomatosis that affects the groins, trochanters, hips, buttocks, and thighs; type 2, the bilateral peritrochanteric familial lipomatoses; and type 3, the unilateral peritrochanteric lipomatosis. This unusual adiposity runs in families and is often accompanied by a psychological reaction due to the disturbed body image. The traditional liposuction is the treatment of choice for these esthetic deformities. The surgical removal of the localized fatty deposit ends with an ugly and unacceptable scars.

\section{Multiple systemic lipomatosis}

Multiple Symmetrical Lipomatosis, also known as Benign Symmetric Lipomatosis or Made lung's Disease and Lanois-Bensaude Syndrome is a metabolic condition characterized by the growth of fatty masses around the face, back of the head, neck, upper arms, abdomen, back and upper leg in a very specific pattern or distribution. Unlike the usual lipoma, these benign, fatty masses are not enclosed within a membranous capsule with very distinct boundaries. It is because of this characteristic, as well as the absolute symmetry in their occurrence that the condition is often dismissed as simple obesity.

The condition seems to manifest itself more during midlife; an obvious question is how many women have this condition with their medical problems being disregarded as psychosomatic or just manifestations of menopause.

Bassetto [14] used the ultrasound-assisted liposuction to treat the multiple systemic lipomatosis. He compared between the traditional lipectomy and the ultrasound-assisted liposuction and concluded that the liposuction can be applied successfully.

\section{Dercum's disease}

It is characterized by the presence of painful adiposity, sleep disturbance, memory impairment, shortness of breath, constipation and fatigue. Dercum's disease is classified into:
Generalized diffuse adiposity, generalized nodular adiposity, localized nodular and juxta-articular as reported by Hansson et al. $[15,16]$.

Women are more affected than men, it is usually appears between the ages of 30 and 50 years, the differential diagnosis includes: familial lipomatosis, multiple symmetric lipomatosis, adipose tissue tumors, panniculitis, lipedema and fibromyalgia. A diagnosis of Dercum's disease is based on patient history and the physical findings. There are no specific laboratory tests for this disease.

Few convincing large studies on the treatment of Dercum's disease have been conducted. Most of the different treatment strategies that exist are based on case reports [17]. Treatment of Dercum's disease is usually targeted towards pain relief rather than lipoma removal. Currently, there is a lack of scientific data on the use of integrative therapies for the treatment or prevention of Dercum's disease.

De Silva [18] used successfully the Liposuction in the treatment of juxta-articular adiposis dolorosa.

\section{Subcutaneous Lipomas}

A lipoma is a benign tumor composed of adipose tissue; it is the most common benign form of soft tissue tumor. Lipomas are soft to the touch, usually movable and are generally painless. Many lipomas are small (under one centimeter diameter) but can enlarge to sizes greater than six centimeters. Lipomas are commonly found in adults from 40 to 60 years of age, but can also be found in younger adults and children.

The author [19] successfully reported the treatment of subcutaneous capsulated giant and moderate sized lipomas by traditional liposuction. The capsule was extracted surgically by the end of the procedure from the same small stab used for liposuction. There was no recurrence, and the cosmetic outcome was highly satisfactory.

\section{Post-traumatic lipomas}

The pathogenetic link between soft tissue trauma and formation of lipomas is still controversially discussed. The first explanation is the prolapsing of the adipose tissue through the fascia defect resulting from direct impact. The second explanation is the formation of adipose tissue as a result of pre-adipocytes differentiation and proliferation mediated by cytokine release following trauma and hematoma formation as described by Austet et al. [20].

\section{Chronic Lymphedema}

There is a physiological imbalance of blood flow and slow lymphatic drainage, resulting in the impaired clearance of lipids and subcutaneous adiposity.

Lymphedema may be inherited (primary) or caused by injury to the lymphatic vessels (secondary). It is most frequently seen after lymph node dissection, surgery and/or radiation therapy, in which damage to the lymphatic system is caused during the treatment of cancer, most notably breast cancer. In many patients with cancer, this condition does not develop until months or even years after therapy have concluded. Lymphedema may also be associated with accidents or certain diseases or problems that may inhibit the lymphatic system from functioning properly. In tropical areas of the world, a common cause of secondary lymphedema is filariasis, a parasitic infection. It 
can also be caused by a compromising of the lymphatic system resulting from cellulitis.

While the exact cause of primary lymphedema is still unknown, it generally occurs due to poorly developed or missing lymph nodes and/or channels in the body. Lymphedema may be present at birth, develop at the onset of puberty (praecox), or not become apparent for many years into adulthood (tarda). In men, lower-limb primary lymphedema is most common, occurring in one or both legs. Some cases of lymphedema may be associated with other vascular abnormalities.

Secondary lymphedema affects both men and women. In women, it is most prevalent in the upper limbs after breast cancer surgery and lymph node dissection, occurring in the arm on the side of the body in which the surgery is performed. In Western countries, secondary lymphedema is most commonly due to cancer treatment. Between 38 and $89 \%$ of breast cancer patients suffer from lymphedema due to axillary lymphnode dissection and/or radiation [21-23], unilateral lymphedema occurs in up to $41 \%$ of patients after gynecologic cancer [24]. For men, a 5-66\% incidence of lymphedema has been reported in patients treated with incidence depending on whether staging or radical removal of lymph glands was done in addition to radiotherapy.

The first report of the use of liposuction to reduce the size of lymphedema of extremity was published by O'Brien [25]; the refinement of the technique was published by Broson [26].

Guidance was used by the National institute for Health and Clinical Excellence in 2008 on the proper indications and patients' selection.

Inclusion criteria for liposuction of lymphoedema of the upper extremity after ablative surgery of the breast as described by Brorson and Freccero [27] are: no pitting, no effect of conservative treatment, no wounds, and no active cancer.

Literatures review concluded that this technique has demonstrated significant and stable reduction of both upper and lower limbs lymphedema. The technique is reliable in treatment of both the acquired and congenital lymphedema.

\section{Axillary hyperhidrosis}

Axillary Hyperhidrosis is the medical term for excessive sweating in the armpit of a person. It is also known as underarm sweating. Axillary Hyperhidrosis involves extreme dripping sweat in the armpits. This sweat is almost totally resistant to all the types of deodorants and other odor controlling medication. There are some other types of Hyperhidrosis which involve various parts of the body like hands feet and face etc. and axillary hyperhidrosis can be present in a person in addition to these parts or may be alone.

The main reason of axillary hyperhidrosis is the over-stimulating of sympathetic nervous system. This condition has direct relation to the mental state of the person and also the environment around his beinganxiety stress emotional stimuli and similar psychological factors pay a great role in enhancing the condition of axillary hyperhidrosis.

Old surgical procedure had many disadvantages with its side effects as they left large scars and was also subjected to long wound healing period. The dressing of these wounds was complex and there was limited motion left for the shoulders of the person who had undergone surgery.

Seo et al. [28] followed-up 43 patients underwent superficial liposuction with currettage for axillary hyperhydrosis, 31 patients
(72.1\%) showed excellent to good results. The most common postoperative complication was transient ecchymosis which spontaneously regressed in 1 to 2 weeks. Focal skin necrosis, in duration, and haematoma or seroma were each noted in four, three, and one patients, respectively, but resolved after proper dressing. The preoperative histological findings included increase in size and number of apocrine glands in cross-section view and the postoperative specimen evidently showed removal of subcutaneous tissue, including apocrine and eccrine glands, and remnant sweat glands were severely destructed.

Seo concluded that tumescent superficial liposuction with curettage for axillary bromhidrosis is an effective and safe treatment method for axillary bromhidrosis.

Ottomann [29] followed up a total of 88 patients; TLC was carried out in 47 and 41 patients received intradermal Botox injections. The effect of both forms of treatment on the quality of life was assessed using a specific hyperhidrosis questionnaire and was correlated with sweat volumes measured by gravimetry. Follow-up after 6 months showed significantly changed sweat volumes of $52+/-41 \mathrm{mg} / \mathrm{min}$ of TLC patients versus $78+/-87 \mathrm{mg} / \mathrm{min}$ in the Botox group. In the TLC group $91 \%$ and in the Botox group $98 \%$ were satisfied with the result. Both methods are superior to other, more radical surgical methods in terms of efficacy and complication rates. Botox and TLC lead to a significant improvement of the quality of life.

\section{Post-ablative surgery}

Autologous fat grafting to the breast for cosmetic and reconstructive purposes is still controversial with respect to its safety and efficacy. Liposuction is considered the ideal harvesting method of the fat graft.

Coleman [30] advocated a unique method for harvesting fat graft. The local anesthesia is most commonly used, but general anesthesia may be preferred for removal of large volume of fat. The preferred donor sites are the abdomen, the inner thigh, the lateral thigh, and the lower back. 15 or $23 \mathrm{~cm}$ two hole Coleman harvesting cannula with a blunt tip and dull distal openings placed extremely close to the end of the cannula is twisted onto a $10 \mathrm{ml}$ Luer-Lok syringe. The combination of slight negative pressure and the curetting action of the cannula motion through the fatty tissue allows parcels of lipoaspirate. The recommended centrifugation of the lipoaspirate is 3000 revolutions per minute for 3 minutes. The middle layer contains the fat cell is used for filling the defects.

Another technique is "The one-step harvesting modification" described by Lazzeri [31]. It is an extremely useful and time-saving method that can be used to ease routine technique in high-volume replacement lipofilling. Furthermore, fat harvested with an a traumatic, low-negative-pressure drain method preserves as many intact and viable lipocytes for transfer as does the manual method using a Luer-Lok syringe, and certainly more than the continuous active suction machine (liposuction). Therefore, it seems reasonable to believe that even when high quantities of fatty tissue are necessary, this method would allow successful long-term graft take anyway, providing durable and predictable cosmetic outcomes in the recipient sites.

Claro et al. [32] conducted a review of literature. Studies included in the review were original articles of autologous liposuctioned fat grafting to the female breast, with description of clinical complications, radiographic changes and local breast cancer recurrence. 
Claro concluded that there was a broad agreement in literature about applicability of autologous fat grafting for breast reconstruction. Complications were few. There was no evidence of interference with follow-up after treatment for breast cancer. Oncological safety remains unclear.

\section{Post irradiated skin}

Radiation dermatitis is a skin disease associated with prolonged exposure to ionizing radiation [33,34]. Radiation dermatitis occurs to some degree in most patients receiving radiation therapy, with or without chemotherapy [35].

There are three specific types of radio dermatitis: acute radio dermatitis, chronic radio dermatitis, and eosinophilic, polymorphic and pruritic eruption associated with radiotherapy. Radiation therapy can also cause radiation cancer.

Radio dermatitis is successfully treated through implantation of fat graft harvested by liposuction tool. The first lipofilling procedure was performed by Coleman [36]. Improvement of skin tropism was reported by Costantino [37] in 2012.

After radiotherapy, breast reconstruction with an implant carries a high risk of failure and complication. Clinical and experimental studies have demonstrated that grafting adipose tissue (lipofilling) in an irradiated area enhances skin trophicity. Sarfati et al. $[38,39]$ have performing preliminary fat grafting to the irradiated chest wall prior to implant reconstruction in order to limit complications and failure risk.

\section{Debulking of flaps}

A bulky appearance is one of the major patient complaints after fasciocutaneous and myocutaneous flaps reconstruction.

Late recontouring of the usual bulky cutaneous flap via conventional liposuction is an accepted practice and usually without fear of tissue necrosis. Single-stage debulking of flaps using suctionassisted lipectomy in combination with skin excision is a safe and reliable procedure with results comparable to conventional multistaged surgical techniques. In 2010, Reuben [40] reported on the efficacy and safety of power assisted suction lipectomy for debulking $f$ fasciocutaneous flaps in upper and lower extremity. Hallock [41-43] successfully reported on the use of the traditional liposuction for debulking of the perforator based muscle flaps, and free flaps as well.

All literature confirmed the efficacy and durability of suctionassisted lipectomy as an adjunctive procedure for flap defatting. The debate is when to start the procedure? It is safe to start the debulking after three months.

\section{Complications of Liposuction}

Severe complications including necrotizing fasciitis [44,], toxic shock syndrome [45], perforation of inner organs [46] and pulmonary embolism [47].These complications were mostly due to inappropriate patient selection, use of excessive local anesthesia during megaliposuction (tumescent technique) and inadequate post-operative surveillance. The complication rate usually reflects a lack of medical experience.

\section{Conclusion}

Liposuction is the most frequent aesthetic procedure worldwide for adipose tissue reduction and treatment of lipedema. It is being employed with increasing frequency. Apart from aesthetic indications, liposuction also is suitable for treatment of chronic medical conditions like lymphedema, benign adipose tissue diseases, Improvement skin vascularity after radio dermatitis, alternate some of surgical procedures like debulking of flaps and as an adjuvant tool for breast reconstruction. This intervention is not a simple procedure but requires extensive knowledge and experience to prevent irreversible medical or aesthetic complications.

\section{References}

1. John W (2011) The Ancient Egyptians for Dummies: Exploring Funerary, Beliefs and Mummification Sons, Ltd. Chichester, West Sussex, England. Chapter 10, page 195.

2. Teimourian B, Fisher JB (1981) Suction curettage to remove excess fat for body contouring. PlastReconstrSurg 68: 50-58.

3. Fournier PF, Otteni FM (1983) Lipo dissection in body sculpturing: the dry procedure. Plast Reconstr Surg 72: 598-609.

4. Illouz YG (1996) History and current concepts of lipoplasty. Clin Plast Surg 23: 721-730.

5. Field LM (1987) the dermatologist and liposuction--a history. J Dermatol Surg Oncol 13: 1040-1041.

6. Dolsky RL, Newman J, Fetzek JR, Anderson RW (1987) Liposuction. History, techniques, and complications. Dermatol Clin 5: 313-333.

7. Klein JA (1990) The tumescent technique. Anesthesia and modified liposuction technique. Dermatol Clin 8: 425-437.

8. Zocchi M (1992) Ultrasonic lipo sculpturing. Aesthetic Plast Surg 16: 287-298.

9. Apfelberg D (1992) Laser-assisted liposuction may benefit surgeons, patients. Clin Laser Mon 10: 193-194.

10. Paul M, Blugerman G, Kreindel M, Mulholland RS (2011) Threedimensional radiofrequency tissue tightening: a proposed mechanism and applications for body contouring. Aesthetic Plast Surg 35: 87-95.

11. Blugerman G, Schavelzon D, Paul MD (2010) A safety and feasibility study of a novel radiofrequency-assisted liposuction technique. Plast Reconstr Surg 125: 998-1006.

12. Sasaki GH (2011) Water-assisted liposuction for body contouring and lipoharvesting: safety and efficacy in 41 consecutive patients. AesthetSurg J 31: 76-88.

13. El-Khatib HA (2008) Unusual distribution of the lower body fatty tissue: classification, treatment, and differential diagnosis. Ann Plast Surg 61: 2-8.

14. Bassetto F, Scarpa C, De Stefano F, Busetto L (2013) Surgical Treatment of Multiple Symmetric Lipomatosis With Ultrasound-Assisted Liposuction. Ann Plast Surg.

15. Hansson E, Svensson H, Brorson H (2011) Liposuction may reduce pain in Dercum's disease (adiposis dolorosa).Pain Med 12: 942-952.

16. Hansson E, Svensson H, Brorson H (2012) Review of Dercum's disease and proposal of diagnostic criteria, diagnostic methods, classification and management. Orphanet J Rare Dis 7: 23.

17. "Dercum's disease". Natural Standard Professional Database. Retrieved 2013-12-22

18. De Silva M, Earley MJ (1990) Liposuction in the treatment of juxtaarticular adiposis dolorosa. Ann Rheum Dis 49: 403-404.

19. Al-basti HA, El-Khatib HA (2002) The use of suction-assisted surgical extraction of moderate and large lipomas: long-term follow-up. Aesthetic Plast Surg 26: 114-117.

20. Aust MC, Spies M, Kall S, Jokuszies A, Gohritz A, et al. (2007) Posttraumatic lipoma: fact or fiction? Skinmed 6: 266-270. 
Citation: Elkhatib HA (2014) Liposuction: A Surgical Tool to Improve the Quality of Life after Morbid Medical Conditions: Review of Literature. Anaplastology 3: 133. doi:10.4172/2161-1173.1000133

Page 5 of 5

21. Brorson H, Ohlin K, Olsson G, Svensson B, Svensson H (2008) Controlled compression and liposuction treatment for lower extremity lymphedema. Lymphology 41: 52-63.

22. Kissin MW, QuercidellaRovere G, Easton D, Westbury G (1986) Risk of lymphoedema following the treatment of breast cancer. Br J Surg 73: 580-584.

23. Segerström K, Bjerle P, Graffman S, Nyström A (1992) Factors that influence the incidence of brachial oedema after treatment of breast cancer. Scand J Plast Reconstr Surg Hand Surg 26: 223-227.

24. Werngren-Elgström M, Lidman D (1994) Lymphoedema of the lower extremities after surgery and radiotherapy for cancer of the cervix. Scand J PlastReconstrSurg Hand Surg 28: 289-293.

25. O'Brien BM, Mellow CG, Khazanchi RK, Dvir E, Kumar V, et al. (1990) Long-term results after microlymphaticovenous anastomoses for the treatment of obstructive lymphedema. Plast Reconstr Surg 85: 562-572.

26. Brorson H (2003) Liposuction in arm lymphedema treatment. Scand J Surg 92: 287-295.

27. Brorson H, Hansson E, Jense E, Freccero C (2012) Development of a pressure-measuring device to optimize compression treatment of lymphedema and evaluation of change in garment pressure with simulated wear and tear. Lymphat Res Biol.2:74-80.

28. Seo SH, Jang BS, Oh CK, Kwon KS, Kim MB (2008) Tumescent superficial liposuction with curettage for treatment of axillary bromhidrosis. J Eur A cad Dermatol Venereol 22: 30-35.

29. Ottomann C, Blazek J, Hartmann B, Muehlberger T (2007) Liposuction curettage versus Botox for axillary hyperhidrosis. A prospective study of the quality of life. Chirurg 78: 356-361.

30. Coleman SR (2001) Structural fat grafts: the ideal filler? Clin Plast Surg 28: 111-119.

31. Lazzeri D, Giannotti G, Colizzi L (2009) One-step fat harvesting method in lipofilling. Plast Reconstr Surg 124: 459e-60e.

32. Claro F Jr, Figueiredo JC, Zampar AG, Pinto-Neto AM (2012) Applicability and safety of autologous fat for reconstruction of the breast.Br J Surg 99: 768-780.

33. James, William; Berger, Timothy; Elston, Dirk (2005). Andrews' Diseases of the Skin: Clinical Dermatology. (10thedn.). Saunders. ISBN 0-7216-2921-0.

34. Bernier J, Bonner J, Vermorken JB, Bensadoun RJ, Dummer R, et al. (2008) Consensus guidelines for the management of radiation dermatitis and coexisting acne-like rash in patients receiving radiotherapy plus EGFR inhibitors for the treatment of squamous cell carcinoma of the head and neck. Ann Oncol 19: 142-149.

35. Coleman SR (1998) Structural fat grafting. Aesthet Surg J 18: 386-388.

36. Coleman SR(1997) Long-term survival of fat transplants: controlled demonstrations. ClinPlast Surg. 2:347-67.

37. Costantino A, Fioramonti P, Ciotti M, Onesti MG (2012) Lipofilling in skin affected by radio dermatitis: clinical and ultrasound aspects. Case report. G Chir33: 186-190.

38. Sarfati I, Ihrai T, Duvernay A, Nos C, Clough K (2013) Autologous fat grafting to the postmastectomy irradiated chest wall prior to breast implant reconstruction: a series of 68 patients. Ann Chir Plast Esthet 58: $35-40$.

39. Sarfati I, Ihrai T, Kaufman G, Nos C, Clough KB (2011) Adipose-tissue grafting to the post-mastectomy irradiated chest wall: preparing the ground for implant reconstruction. J Plast Reconstr Aesthet Surg 64: 1161-1166.

40. Reuben CM, Bastidas N, Sharma S (2010) Power-assisted suction lipectomy of fasciocutaneous flaps in the extremities. Ann Plast Surg 65: 60-65.

41. Hallock GG (2004) Conventional liposuction-assisted debulking of muscle perforator flaps. Ann Plast Surg 53: 39-43.

42. Hallock GG (1986) Liposuction for debulking free flaps. J Reconstr Micro Surg 2: 235-239.

43. Hallock GG (1985) Defatting of flaps by means of suction-assisted lipectomy. Plast Reconstr Surg 76: 948-952.

44. Gonzáles Alana I, Marin de la Cruz D, Palao Doménech R, BarretNerin JP (2007) Necrotizing fasciitis after liposuction. Acta Chir Plast 49: 99-102.

45. Di Candia M, Malata CM (2011) Aesthetic and functional abdominal wall reconstruction after multiple bowel perforations secondary to liposuction. Aesthetic Plast Surg 35: 274-277.

46. Holm C, Mühlbauer W (1998) Toxic shock syndrome in plastic surgery patients: case report and review of the literature. Aesthetic Plast Surg 22: 180-184.

47. Zeidman M, Durand P, Kundu N, Doumit G (2013) Fat embolism after liposuction in Klippel-Trenaunay syndrome. J Craniofac Surg 24: 1319-1321. 